\title{
Heavy Duty Marine Carousel Structure Analysis Based on Finite Element Theory with Multi Pivot-Nonlinear Support
}

\author{
Pei Zheng \\ Scientific Research Academy, ShangHai Maritime University, Shanghai, P.R.China \\ baby.zp@163.com
}

Keywords: Carousel, Nonlinear, Only- Compression, Simulation.

\begin{abstract}
In this paper, with 2500 tons of Heavy Carousel pipe laying equipment as the object of analysis, research under action of different wave, using the finite element method calculation of statically indeterminate and multi support and contact nonlinear support overloaded basket, the structure of the foundation as well as the intensity of supporting wheel bearing capacity on different stiffness of rubber pads, to ensure that the heavy-duty pipe laying equipment can be safely and efficient use.
\end{abstract}

\section{Introduction}

As China's offshore oil field on the degree of openness of the depth step by step, after more than twenty years on the offshore pipe laying technology. Research on the development of equipment, submarine pipeline laying technology in China has great development ${ }^{[1]}$. With the development of large-scale ships, pipe laying equipment is also more and more to the heavy load, high speed, efficient development trend. As marine engineering construction, an integral part of the study, the laying of submarine pipeline and special equipment, is one of the important research contents in the field of Offshore Oil Engineering

Using reel laying device, carousel will be matched with the vertical laying system for deepwater flexible pipe from the moon pool laying ${ }^{[2]}$. The method of laying speed, and pipeline welding work on land controlled environmental conditions. Today the European Marine powers have begun to use in a new generation of high-speed, overloaded reel pipe laying equipment

\section{Heavy duty carousel pipe laying device}

The carousel shall be a basket type structure, which rotates on a king pin (vertical axis), and is supported and runs on several rows of rollers. The carousel shall be mainly composed of basket structure, foundation structure, king pin etc.

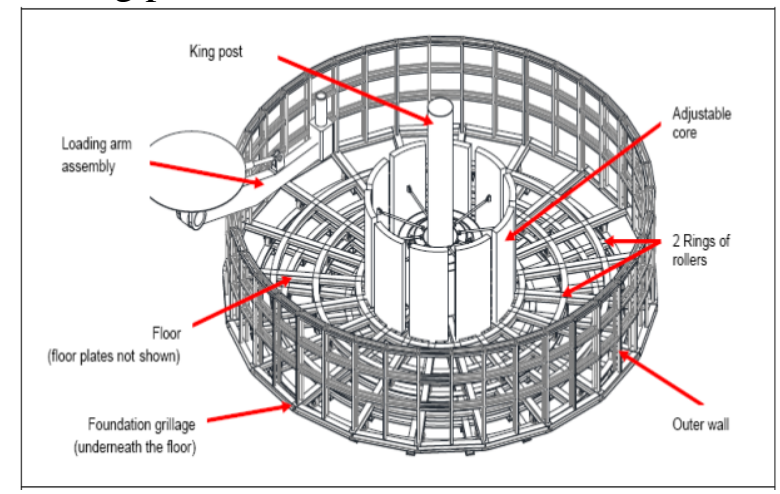

Figure.1 Main structural parts of carousel

The basket structure is the main part of carousel, storing flexible pipe, umbilical cable, cable or large-diameter fiber rope and with adequate strength to bear the load caused by the vessel motion in the operation condition and survival condition. The basket structure will be supported on the steel foundation by rollers. The foundation shall be with adequate strength. Several rows of rollers shall be 
fitted concentric on the foundation. Each row shall be with necessary amount of rollers, arranged circumferentially, to ensure the basket structure rotating smoothly.

The king pin shall be installed on the center of the foundation, located in the inner wall of basket structure. The king pin will be based on a pillar of vessel structure. The king pin and its installation shall be with adequate strength, to bear the radial load caused by the vessel motion in the survival condition. It can be seen from Figure 1 that shows the main structural parts of carousel.

As marine engineering construction, an integral part of the study, the laying of submarine pipeline and special equipment, is one of the important research contents in the field of Offshore Oil Engineering.

\section{Structure analysis of finite element simulation of Carousel}

Based on the 2500T-Carousel structure drawings, the finite element model is built on ANSYS software. The carousel finite element model, located between the multi-layer cable enclosure and when the carousel is subjected to the transverse acceleration, transfer cable to basket and king pin force is a nonlinear, consolidation and contact coupling problem. This paper will adopt the only-way stress nonlinear element to simulate.

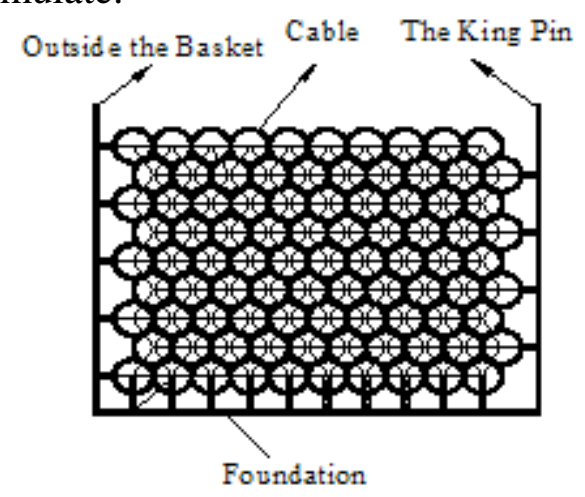

- Only Compression - Only Axial Force

Figure.2 Force transmission simulation of cable

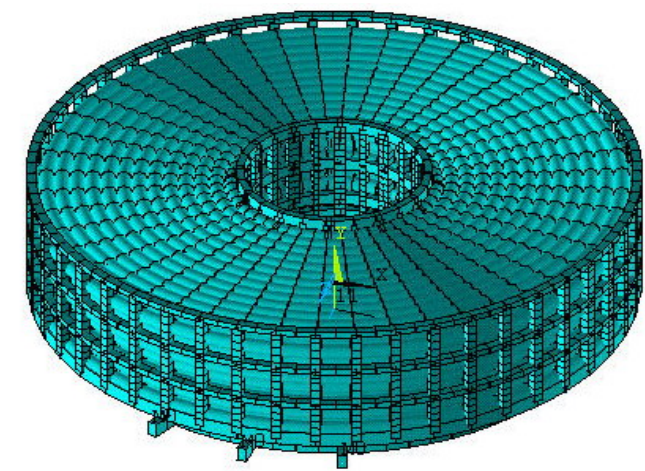

Figure.3 Finite element simulation of carousel

Figure 2 shows the force transmission simulation of cable on FEA model ${ }^{[3]}$. The cable is connected with the basket outside, the bottom of foundation and king pin by only-compression element. When the overall structure and the horizontal acceleration due to gravity, unidirectional stress element is available with only compression, Tension means to separate structural components in its contact cable.

Between the cable and the cable adopts an axial force element, on the lower use of connection form an equilateral triangle, is used to simulate the cable under the action of gravity itself produces to the fence and the shaft core to generate pressure. Because the cable and connected to the unidirectional stress element under gravity and lateral acceleration load, finite element program will be based on the cable to generate pressing and separation tendency of automatic iterative calculation of tension and compression element characteristics. 
Base foundation wheel is also used in unidirectional compression unit, through nonlinear finite element calculation of wheel uneven stress situation. In order to ensure the base supporting wheel can load more average bear from the upper part of the supporting wheel is arranged at the bottom, in the rubber. The figure 3 shows FEA model on ANSYS.

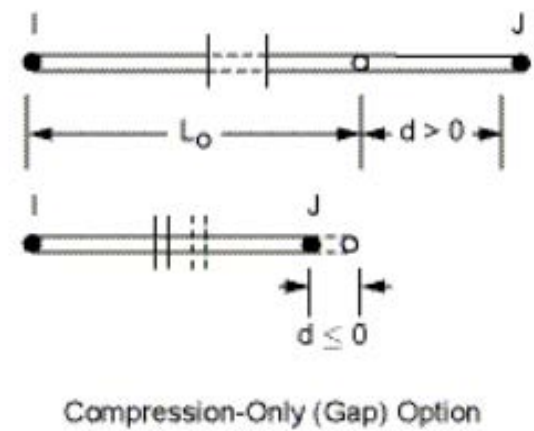

Figure.4 Only-way element description

\section{Finite Element Theory with Nonlinear Only-way}

\section{a. Nonlinear Only-way}

With the compression-only option, the stiffness is removed if the element goes into tension (simulating a slack cable or slack chain condition). This feature is useful for static guy-wire applications $^{[4]}$ where the entire guy wire is modeled with one element. Based on the finite displacement theory, the generalized pole system nonlinear finite element structural geometry method, cyclic iteration is carried out based on the increment of initial strain of cable force adjustment method, can affect the geometric nonlinearity, accurate calculation and structure after group of pre-stressed reinforcement tension on the tendons tension loss and other factors.

The figure 4 is the description about this nonlinear element.

The element applied load vector is:

$$
\{F\}=A E \varepsilon^{T}\left[\begin{array}{llllll}
-C_{1} & 0 & 0 & C_{1} & 0 & 0
\end{array}\right]^{T}
$$

Where: $\varepsilon^{T}=a \Delta T-\varepsilon^{\text {in }}, a=$ coefficient of thermal expansion, $\Delta T=$ Temperature difference,

$$
\varepsilon^{\text {in }}=\text { pre-strain. }
$$

b. Finite element equilibrium equation

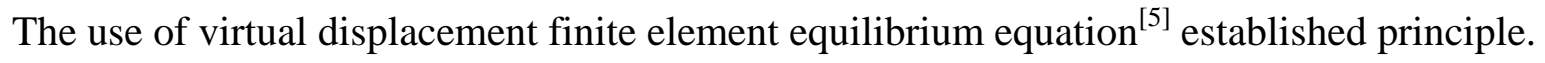

$$
\int_{V} \delta\{\varepsilon\}^{T}\{\sigma\} d V=\delta\{d\}^{T}\{F\}
$$

In the formula: $\delta\{d\}^{T}$ - Virtual displacement of node, $\delta\{\varepsilon\}^{T}$ - Virtual strain, $\{F\}$-Lad vector of node, when $\delta\{d\}^{T}=[\bar{B}]^{T} \delta\{\varepsilon\}$, we can get a general balance equations of nonlinear problems

$$
\{\Psi\{d\}\}=\int_{V}[\bar{B}]^{T}\{\sigma\} d V-\{F\}=0
$$

Integral calculation formula (3) is the one by one unit, and according to the conventional method of superposition of them on node balance effect.

c. Foundation wheel with nonlinear support

Foundation wheel is also used in uniaxial compression unit, through nonlinear finite element calculation of wheel uneven stress situation ${ }^{[6]}$. Figure 5 shows a seat with a finite element model of the supporting wheel. In order to ensure the supporting wheel can load more average to bear from the 
upper part, the No.1 rubber (as showen figure 6) is arranged at the bottom of wheel. In the model, according to the load, area and the amount of compression about rubber, the elastic modulus of non metallic element is established.

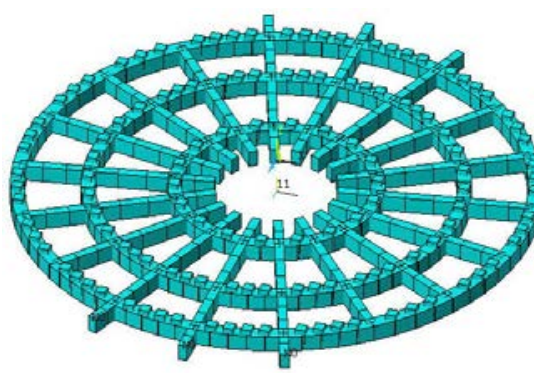

Figure.5 FEA description of wheel

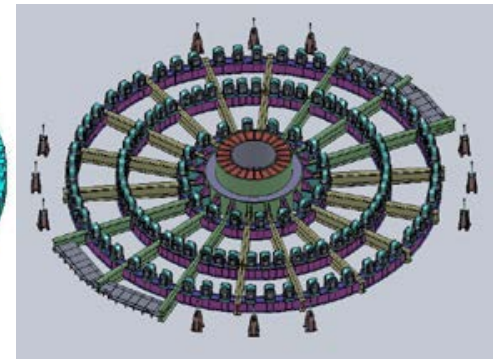

Figure.6 Stiffness of rubber

\section{Results of Simulation}

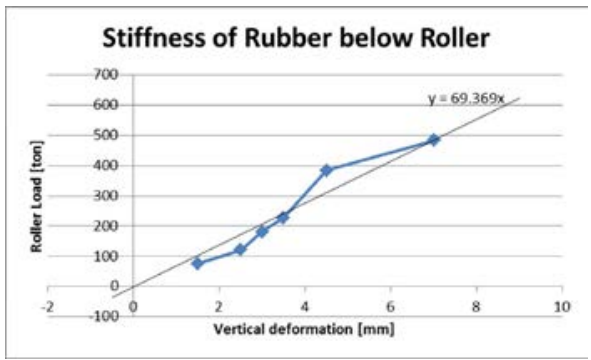

Table 1 Acceleration load

\begin{tabular}{|c|c|c|}
\hline & Working conditions & Survival condition \\
\hline Longitudinal & $0.026 \mathrm{~g}$ & $0.102 \mathrm{~g}$ \\
\hline Transverse & $0.155 \mathrm{~g}$ & $0.725 \mathrm{~g}$ \\
\hline Vertical & $1.172 \mathrm{~g}$ & $1.803 \mathrm{~g}$ \\
\hline
\end{tabular}

Pipe laying ship in its operation process are mainly in the following two states. By loading in different directions acceleration in the form of finite element model, we can get two kinds of load combinations to calculate (table 1 ).

Carousel foundation is welded with the bottom surface of the cabin, constraints on the foundation, at the same time to ensure the stability and convergence of the model calculation, the need for ROTY constraint ${ }^{[7]}$

on the side of the basket; the center of the base and the king pin with rigid coupling is used to transfer the horizontal load.

According to the model analysis and the finite element calculation results, The strength of basket and the pressure force of foundation wheels are most important check content. Figure 7 shows the basket stress distribution under two conditions.

The survival condition of foundation wheels stress value is much higher than the working conditions, so the figure 8 is pressure force distribution by the survival condition.

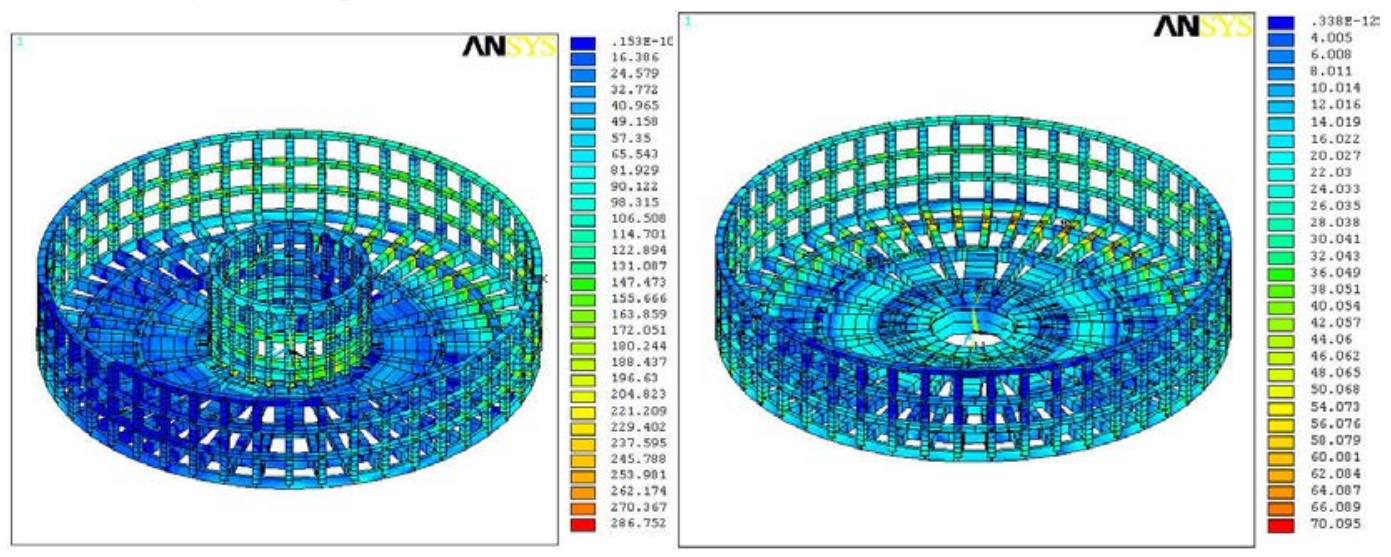

Figure.7 Stress results of basket 

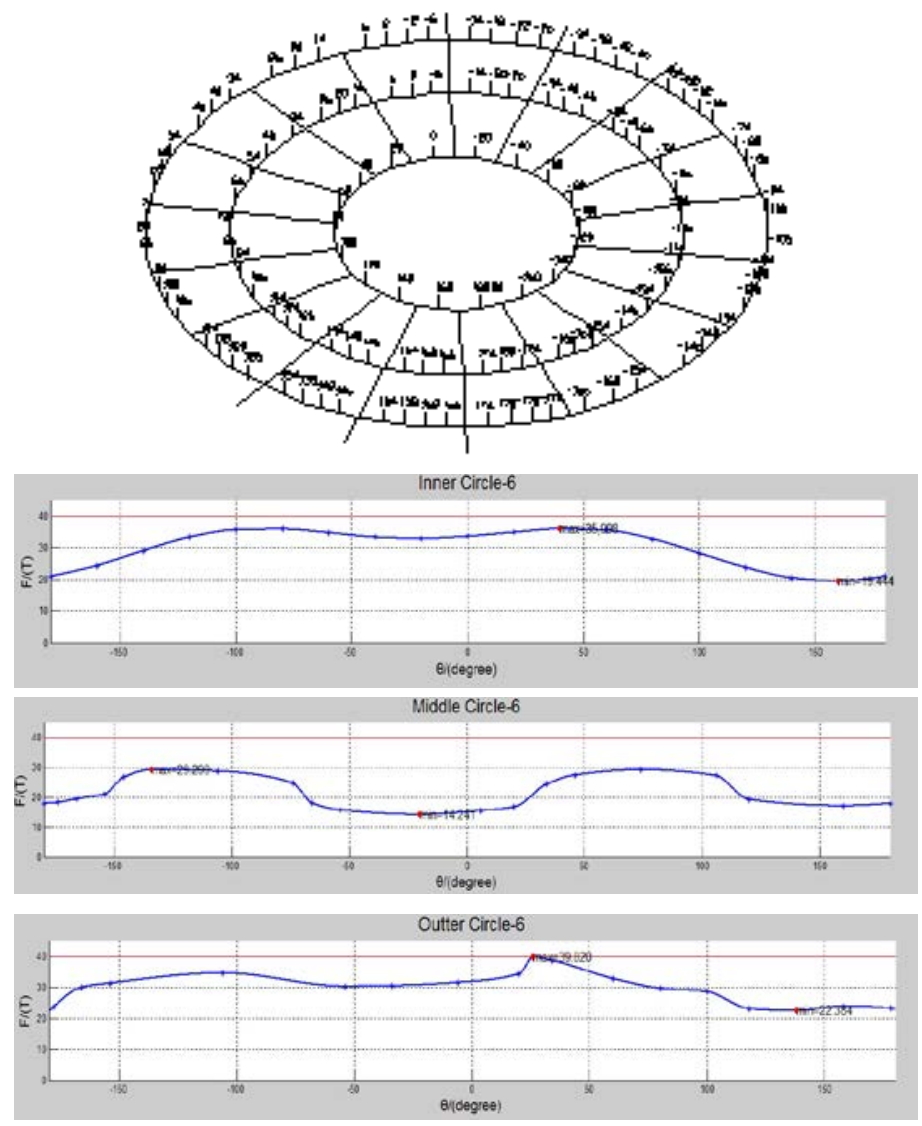

Figure.8 Pressure force of foundation wheels

\section{Conclusion}

Based on the finite element calculation result, cable stiffness size, rubber thickness choice for carousel enclosure structure as well as the base of supporting wheel pressure distribution has decisive influence, mainly manifested in the following aspects

1) Beam elements are included in the model, representing the cables in the basket. These beam elements are connected with link elements. The stiffness of the whole package of beam elements and link elements in the model is rather high. Deformation of the outer and inner wall of the basket is only possible when the cable package is flexible. The inertia load from the cables is not transferred into the basket structure properly in this FEA, due to the high stiffness of the cable package. The deformations and stresses in the basket construction will be different in reality. Lower stiffness of the coupling beams resulted in more realistic deformations. Coupling between the cables should be made less stiff to get realistic results.

2) Rubber pads are applied below the roller brackets. These pads should have enough flexibility to compensate for deviations in the flatness of the rail plates and for deviations in the height position of the rollers. Educe the stiffness of the pads by: reduction of area of flexible material, and/or change the material type and/or increase thickness of the flexible material. The rollers are designed for 80.3 ton in survival condition $>\mathrm{F}=78.65 \mathrm{t}$ (maximal pressure force of FEA model). The current rubber stiffness choice and roller arrangement are suitable.

3) According to the CCS Specification ${ }^{[8]}$, Carousel survival condition can be regarded as III condition, with 1.15 times safety coefficient. The carousel main structure allowable stress should be $355 / 1.15=308.6 \mathrm{MPa}>286.75 \mathrm{MPa}$ (structure calculation of maximum stress) on survival condition. The main carousel structure allowable stress is calculated as $355 / 1.50=236.6 \mathrm{MPa}>70.1 \mathrm{MP}$ on the operating condition. By calculation, the 2500T-Carousel structure can meet the requirements specified in the structure strength condition and has certain safety factor. 


\section{Acknowledgements,}

Shanghai Youth Teacher Program (B2120053050X)

National High Technology Research and Development Program (863 Program), (SS2013AA041106),

\section{References}

[1] Qu Jun Sheng, Liu Wen Li, Cai Lian Bo. The Development of Our Country and Submarine Pipeline Laying Pipe . China Water Transport, 2013, Vol.13

[2] Dang Xue-bo, Gong Shun-feng, Jin Wei-liang. Research Progress on Submarine Pipeline Laying Technology. China Offshore Platform, 2010, Vol.25

[3] ANSYS Inc. ANSYS Incorporated Handbook. 2000.2

[4] Tedesco J W, W G Mc Dougal, C A Ross. Structural Dynamics. Theory and Applications: Addison Wesley Longman In, 1999

[5] Dynamics of Structures Secind Edition. Berkeley: California 1995

[6] Tang You Gang. Dynamics of Structure Advanced Dynamics of Structures Advancd Dynamics of Structures. Tian Jin, Tian Jin Uinversity Press, 2002.12

[7] H.L. Ren, X.L. Wang, Y.J. Hu and C.G. Li. Dynamic Response Simulation of Lifting Load System of Ship-mounted Cranes. Journal of System Simulation, 2007, 39(12): 145 150.

[8] Ships and Offshore Lifting Equipment Specification. CCS- 2001 